\title{
Identification of Herniated Nucleus Pulposis in Spinal Cord Injury
}

\author{
D. F. Apple, Jr., M.D., A. P. McDonald, M.D., R. A. Smith, M.D. \\ Georgia Regional Spinal Cord Injury System, Shepherd Spinal Center, 2020 \\ Peachtree Road, Atlanta, Georgia, U.S.A.
}

\section{Summary \\ Five cases of documented traumatic herniated nucleus pulposis are presented all occurring within the cervical region. The incidence of herniated disc in cervical spinal cord injury is $0 \cdot 7^{\circ}$. The incidence of herniated disc in bilateral facet dislo- cations is $2 \cdot 3^{\circ}{ }_{0}$. The common features are radicular pain, incomplete syndrome, and bilateral facet dislocations. A routine myelogram is the most helpful test to establish the diagnosis.}

Key words: Traumatic herniated nucleus pulposis; Cervical spine injury.

\section{Introduction}

Stookey in 1927, published a group of unusual tumours arising from the intervertebral disc. He described them as 'discrete, sharply circumscribed, ventral, extradural chondromas lying in the midline or slightly to the side of midline, usually in the region of the 4th, 5th, and 6th cervical vertebra.' He described the symptomatology as usually marked unilateral spasticity with atrophy and weakness of the muscles of one or two cervical segments with change in pain and temperature sense on the opposite side. He felt that if the growth was more lateral compression was exerted primarily on the nerve root and the only neurologic signs were those referable to involvement of the isolated nerve root. Schmorl, and also Dandy, both in 1929, wrote of their experience with chondromas indicating that it was more common in the lumbar area than the cervical region. Mixter and Barr in 1934, published a series of herniated discs treated surgically which popularised this treatment.

Little has been written about disc rupture in spinal cord injury although early surgeons alluded to the problem as justification for laminectomy to relieve cord compression. Schneider and Kahn in 1956, looking at the neurological sequelae of acute trauma to the spinal cord did not mention disc rupture and indeed it does not seem to be common. In 10 years, 657 patients with cervical spinal cord injury have been treated at the Shepherd Spinal Center, the Georgia Regional 
Spinal Injury Center. Five cases of symptomatic herniated disc following injury have been documented and will be presented.

One of the earlier descriptions of spinal cord injury secondary to bilateral facet dislocations was presented by Butcher in 1853. Seven cases of spinal dislocation were presented having had autopsies performed. Nothing was found at autopsy which could have been herniated disc material.

Cramer (1943) described one patient with a compression fracture in the cervical region who had a proven disc at surgery. In 1955 O'Connell reporting on the involvement of the spinal cord by intervertebral disc protrusions identified two out of 16 patients who had quadriparesis following spinal column trauma. One of these had a herniated disc between the 5th and 6th cervical vertebra proven at autopsy. The other had narrowing at the C6-7 level on plain films with a normal myelogram and spontaneous resolution of the symptoms without surgery. Barnes in 1948, reporting on paralysis in cervical spine injuries mentioned three cases of acute retropulsion of the disc but only one of these was proven at surgery. The other two showed considerable recovery of paralysis without operative treatment. In 1956, Schneider and Kahn discussing five cases of acute flexion or 'tear drop' fracture dislocation of the cervical spine had no disc protrusions. Durbin in 1957 analysing 75 patients with fracture dislocations of the cervical spine had one case of questionable herniated nucleus pulposis.

Schneider (1958) reporting on 12 cases of central cord syndrome found no evidence of herniated nucleus pulposis as either an etiology or as a complicating finding. Forsythe (1959) reported 52 patients with bilateral facet dislocations. None of these had a herniated nucleus pulposis. Cloward (1961) reported eleven patients with acute injury to the cervical spine, 10 having motor or sensory impairment. One of these patients was found to have a ruptured disc below the level of the spinal dislocation. Braakman (1967) reported 37 cases of unilateral facet dislocations with no patient having a herniated nucleus pulposis. Schneider (1973) reporting 17 cases of traumatic spinal cord syndromes listed one case of a fracture dislocation of $\mathrm{C} 5$. No herniated disc was found at surgery but at autopsy, an extruded disc was found in the canal.

One study specifically looking for compression secondary to acute disc protrusion and trauma was done by Raynor in 1977. Twenty consecutive patients underwent myelography shortly after injury. Nine of these patients demonstrated disc protrusion. All of these patients had a central cord syndrome presentation. Four of these patients showed neurological improvement, usually manifested by the 5th day. Allen, in 1985, reported on 46 patients with acute non-penetrating cervical spinal cord injuries who were evaluated by computerised tomography with metrizamide myelography. Two patients were identified as having an anterior herniated discs causing compromise of the cord.

\section{Case Reports}

Between 1975 and 1985, five patients at the Shepherd Spinal Center with cervical spinal cord injury were diagnosed as having a herniated disc subsequently proved at surgery. The case reports follow:

1. A.J., a 22-year-old female injured in an automobile accident on 10-29-78 sustained a C5-6 bilateral facet dislocation. Neurological examination 


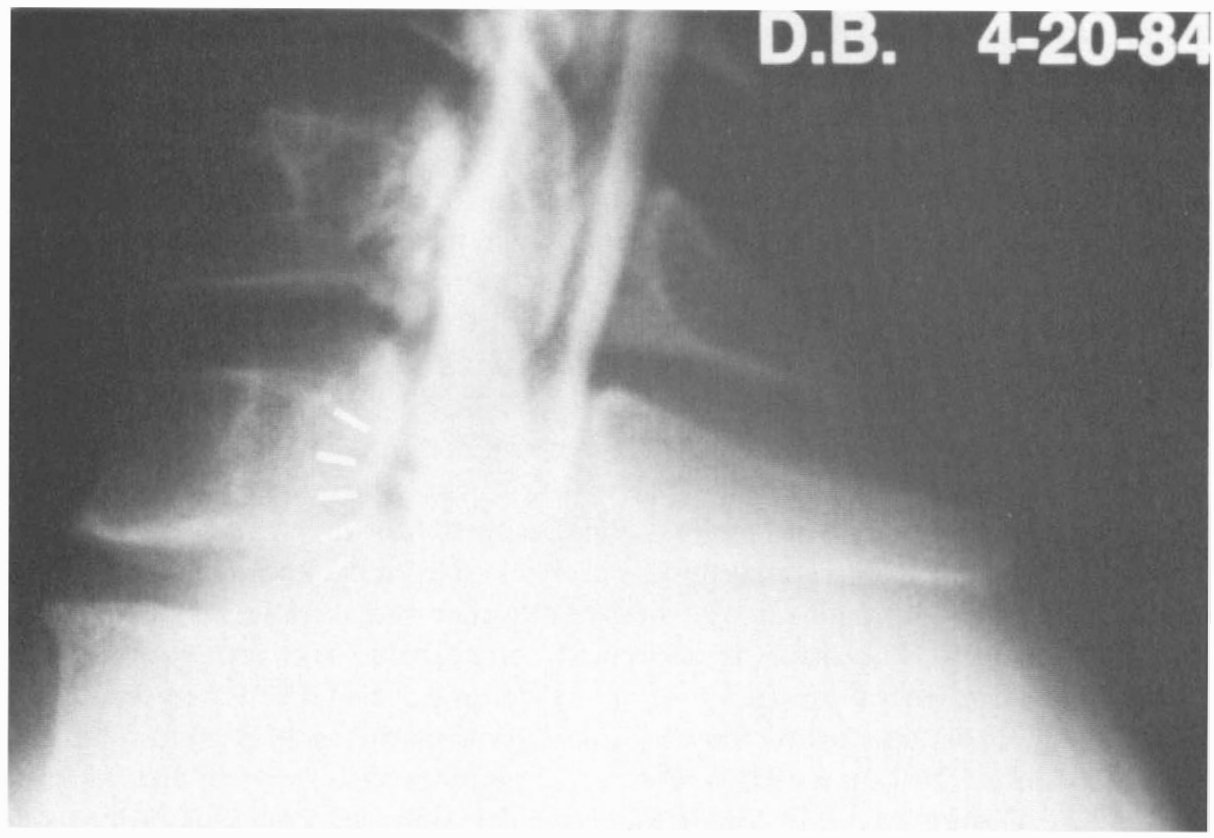

Figure 1a Lateral of cervical myelogram showing defect at C6-7.

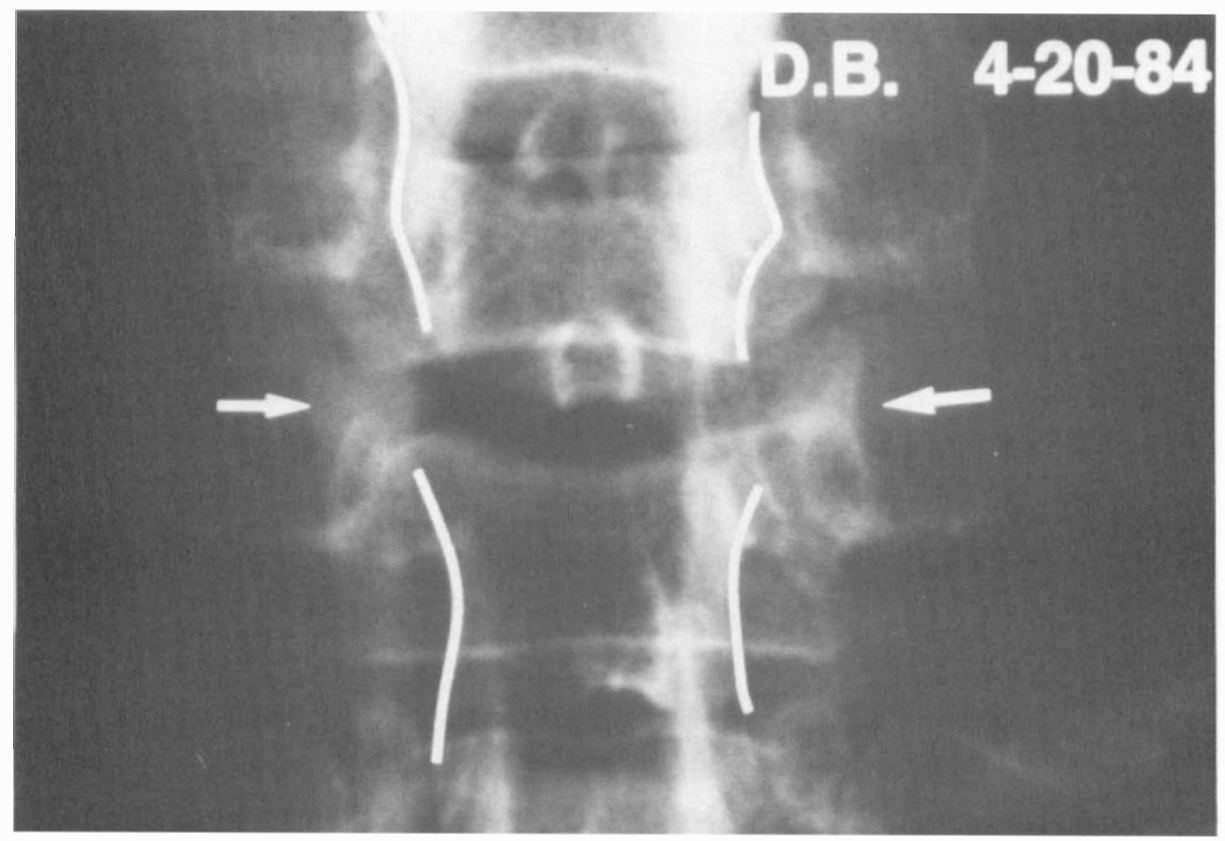

Figure 1b A-P of cervical myelogram showing defect on right. 
revealed a Brown-Sequard syndrome (Frankel D). She steadily regained neurological function after closed reduction and on 11-9-78 had posterior cervical wiring and fusion. In the immediate postoperative course, her function was lost to her admission presentation. A myelogram done the same day was positive for disc compression at C5-6. Anterior discectomy revealed ruptured disc material on the left side. She was discharged on 1215-78 Frankel E.

2. D.B., a 29-year-old male was struck in the neck at work on 4-9-84 causing a Brown-Sequard syndrome (Frankel D) with normal roentgenograms. On 4-19-84 a computerised scan with metrizamide was normal. There was no evidence of neurological improvement with continued complaints of neck pain. On 4-20-84, (Fig. 1a, 1b) a myelogram was performed showing a ventral defect at C6-7 on the right and anterior cervical discectomy and fusion was performed on 4-24-84. The patient was discharged on 5-23-84 Frankel E.

3. J.S., a 25-year-old male who was driving on 6-7-84 when he was thrown from the car sustaining C7-T1 bilateral facet dislocation. He was graded Frankel B. Because of inability to reduce his bilateral dislocation closed, he had an open reduction, posterior cervical writing and fusion performed on 6-8-84. One week post-operative he began getting up and immediately complained of pain in his left arm on each occasion. On 6-18-84, (Fig. 2a, $2 b)$ a myelogram demonstrated an extradural defect at C6-7 on the left. On 6-22-84, he had anterior cervical fusion with removal of a herniated disc. He was discharged from the hospital on 9-1-84 with his pain relieved but still Frankel B.

4. M.H., a 25-year-old male sustained a C5-6 injury on 6-17-84 following a diving accident. He was graded Frankel $A$. Routine roentgenograms showed multiple facet fractures at $\mathrm{C} 4,5$ and 6 . He was placed in Gardner-Wells traction to be followed by a halo jacket. However, he continued to complain of severe pain in his left arm which was not relieved by positioning, altering the amount of traction of facet blocks. A CAT scan with metrizamide injected from below was done on June 18 th showing the canal to be patent. His complaints continued and on 6-24-84, a myelogram was done using C1-2 injection and was not diagnostic. His left arm pain persisted. Therefore on 7-10-84, an anterior cervical fusion was performed and a large disc was found on the left side. He was discharged from the hospital on 10-25-84 Frankel A.

5. E.E., a 32-year-old male was involved in an automatobile accident on 4-22-85 sustaining a C5-6 bilateral facet dislocation. He was graded a Frankel B. He was placed in traction with increasing weight but could not be reduced. On 423-85, he had an open reduction with posterior wiring and fusion. His neurological picture improved in both upper and lower extremities but he continued to complain of radicular pain on the right side. A myelogram was performed on 5-10-85 (Fig. 3a, 3b) which showed a ventral, bilateral extradural deformity at C5-6. On 5-17-85, he had an anterior bilateral extradural deformity at C5-6. On 5-17-85, he had an anterior cervical operation with removal of a herniated disc and a fusion was performed. He was discharged on 8-25-85 free of pain as a Frankel D. 


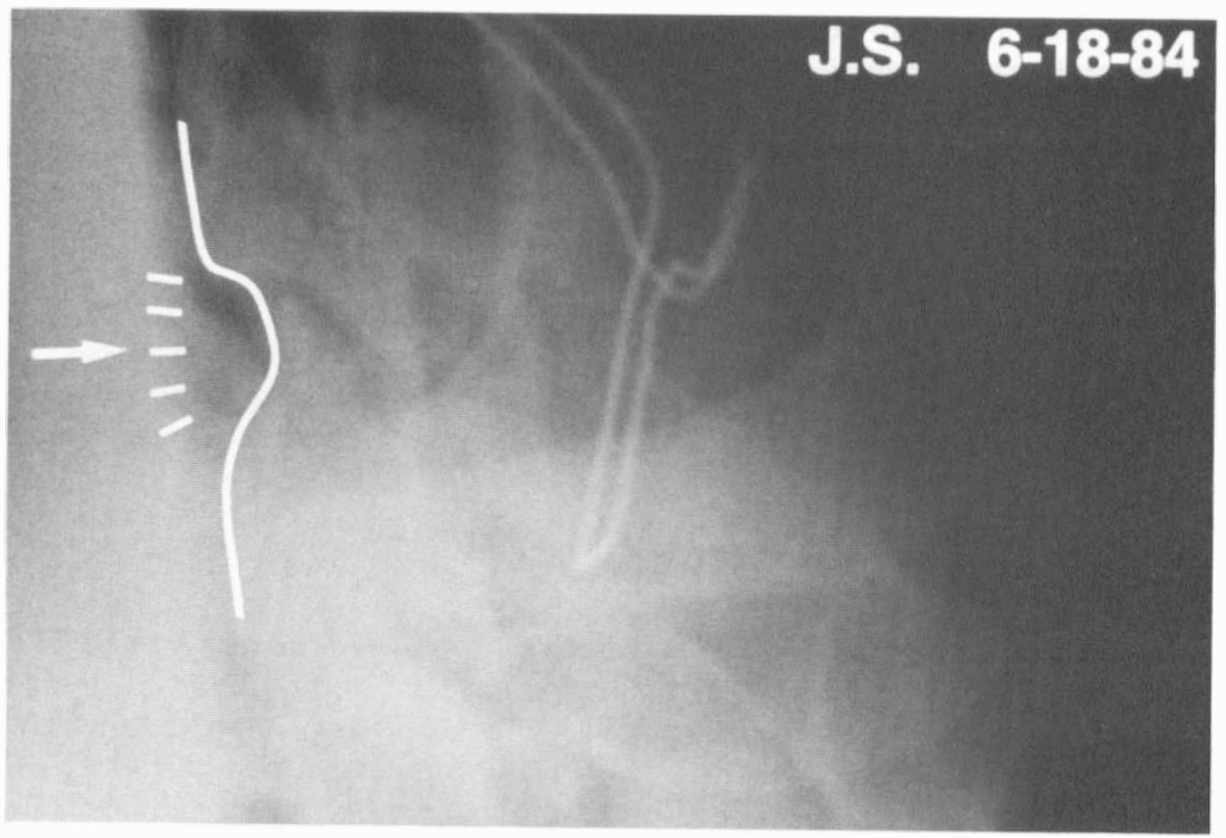

Figure 2a Lateral of cervical myelogram showing defect at C6-7.

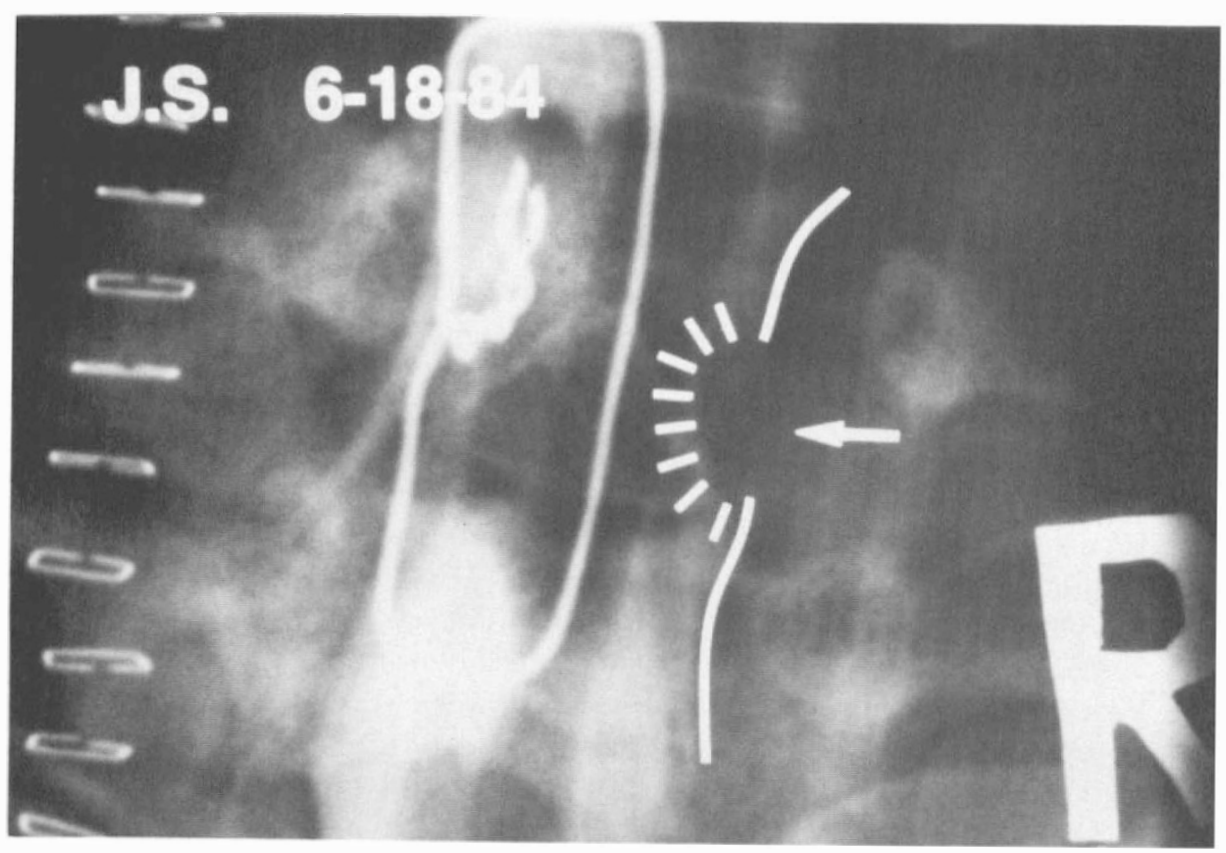

Figure 2b A-P of cervical myelogram showing defect on right. 


\section{E.E. 5-10-85}

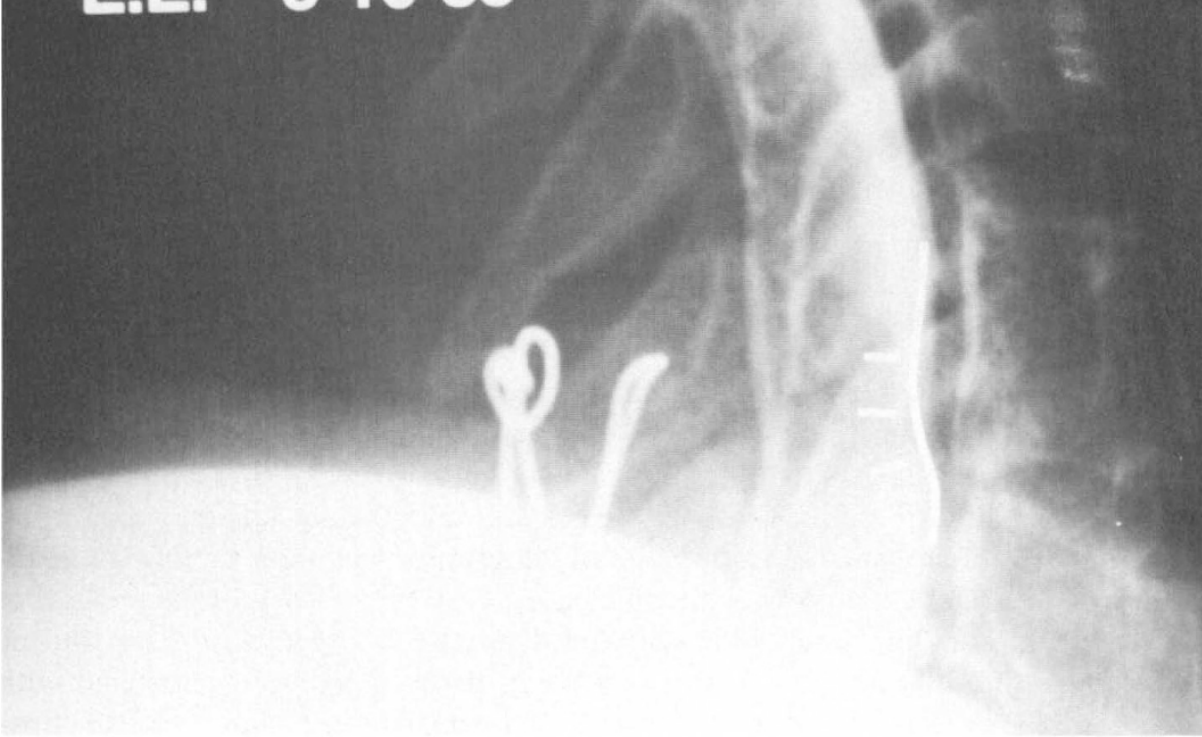

Figure 3a Lateral of cervical myelogram showing defect at C5-6.

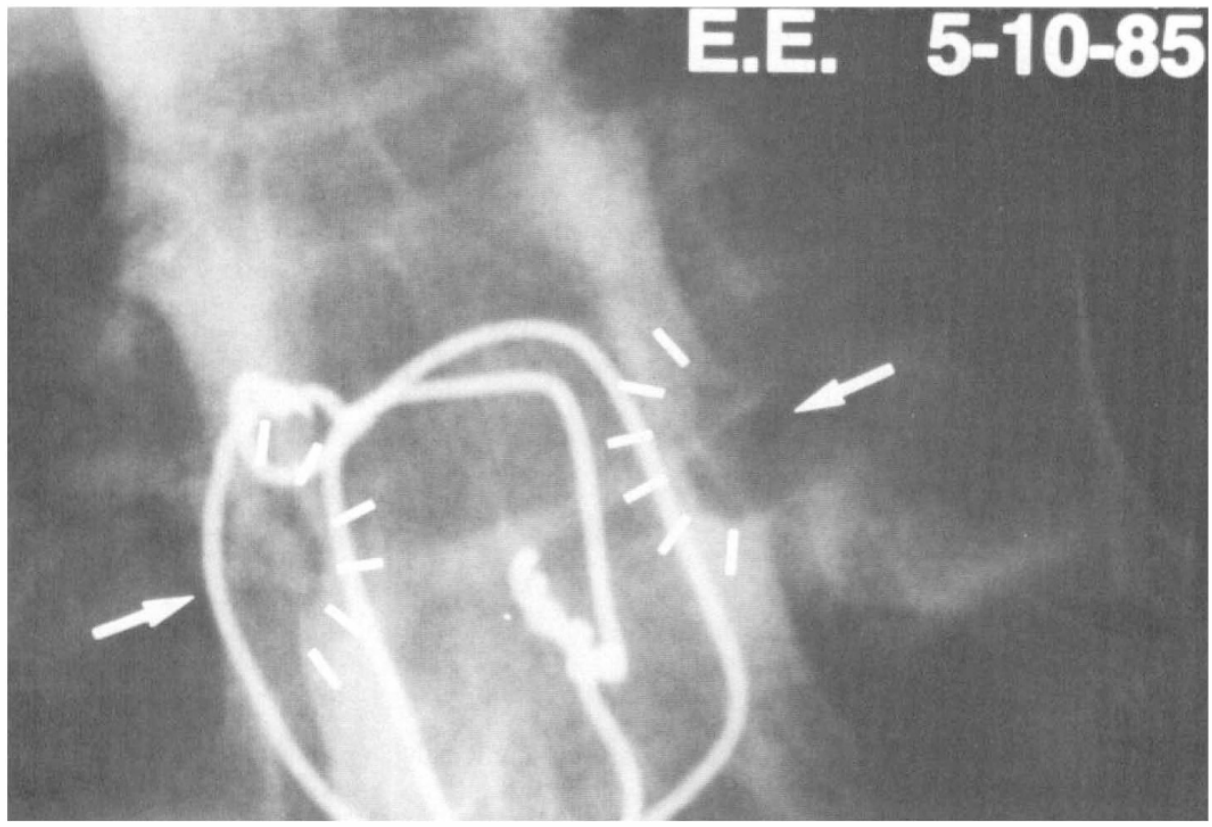

Figure 3b A-P of cervical myelogram showing bilateral defect at C5-6. 


\section{Discussion}

Herniated disc as a problem in spinal cord injury is not common. In discussing the problem with Meyer (personal communication) and Eismont (personal communication) they could collectively identify only 11 cases, all of these being in the cervical region except two at the thoracic lumbar junction in Meyer's series. The incidence in this series is $0.7^{\circ}{ }_{0}$ of cervical injuries, and $0.4^{\circ}{ }_{0}$ of all injuries. Analysis of these five cases shows that four of the five had radicular pain with three having incomplete spinal syndromes. In Cloward's series (1961) all of the patients complained of pain in the neck and shoulders and in one or both upper extremities. Pain was relieved by traction in many of these patients. In nine of 10 patients in Cloward's series surgery completely relieved the pain immediately following surgery or by the time the patient was discharged from the hospital. Other indicators of a herniated disc, i.e., weakness, sensory and reflex changes, were already altered by the spinal cord injury in this series of patients and could not be utilised for diagnosis. Since these indicators are not reliable, this may mean that some disc problems are being missed. Myelography was most helpful in establishing the diagnosis in four of the five cases. However, based on the review of the literature and this small series, it would be difficult to recommend routine myelography in all patients. With the advent of the CAT scan enhanced with metrizamide myelography and now magnetic resonance imaging, it may be possible to determine which routine studies are better medically and economically.

Three of the five patients had bilateral facet dislocations. In Raynor's series (1977) three of the eight who had surgery for disc protrusion had bilateral facet dislocations. In Allen's series (1985) of evaluation with CT metrizamide myelography, there were no cases of pure dislocation. One of the patients with proven disc had a fracture dislocation and in another no fracture identified. Of the 657 cervical injuries seen at the Shepherd Spinal Center, there were 126 bilateral facet dislocations. This gives an incidence of herniated discs with bilateral facet dislocation of $2 \cdot 3^{\circ}{ }^{\circ}$. Since a bilateral facet dislocation has to disrupt the disc space, it is surprising that more disc problems are not encountered. If there is no indication to do myelography, it might be worthwhile to obtain a myelogram prior to posterior wiring and fusion of bilateral facet dislocations. More experience with magnetic resonance imaging may prove this to be the diagnostic procedure of choice. Three of the five patients showed neurological improvement, but only in one case is it felt that the herniated disc played any part in the neurological problem.

\section{References}

Allen RL, Perot PL, Gudeman SK (Oct) 1985 Evaluation of acute nonpenetrating cervical spinal cord injuries with C.T. metrizamide myelography. Fournal of Neurosurgery 63:510.

BARNES R (May) 1948 Paraplegia in cervical spine injuries. Fournal of Bone and foint Surgery 30B:234.

BRAAKMAN RP, VINKEN PJ (May) 1967 Unilateral facet interlocking in the lower cervical spine. fournal of Bone and foint Surgery 49B:249.

BUTCHER RGH 1853 On dislocation of the cervical vertebrae without fracture. Dublin fournal of Medical Science 15:383.

ClOWARD RB 1961 Treatment of acute fractures and fracture-dislocations of the cervical spine by vertebral body fusion. Fournal of Neurosurgery 18:201.

Cramer F, McGowan FJ 1944 The role of the nucleus pulposus in the pathogenesis of so-called recoil injuries of the spinal cord. Surgery Gynecology and Obstetrics 79:516. 
DANDY WE (Oct) 1929 Loose cartilage from intervertebral disc, simulating tumor of the spinal cord, Archives of Surgery 19:660.

Durbin FC (Feb) 1957 Fracture Dislocations of the Cervical Spine, fournal of Bone and foint Surgery 39B:23.

EISMONT F Personal communication.

FoRSYTHE HF, AlEXANDER E, et al., (Jan) 1959 The advantages of early spine fusion in the treatment of fracture dislocations of the cervical spine, fournal of Bone and foint Surgery 41 A:17.

MEYER PR Personal communication.

MiXTER WJ, BARR JS (Aug) 1934 Rupture of the intervertebral disc with involvement of the spinal canal, New England fournal of Medicine 211:210.

O'CoNNELl JEA (Nov) 1955 Involvement of the spinal cord by intervertebral disc protrusions, British fournal of Surgeons 43:225.

RAYNOR RB (Mar) 1977 Compression secondary to acute disc protrusion in trauma Spine 2:39.

SCHMORL G 1929 Uber Knorpelknoten an der Hinterflache der Werbelbandscheiben Fortschr a.d. Geb. d. Rontgenstrahlen 40:627.

SChNEIDER RC. Crosby FC, et al. 1973 Traumatic Spinal Cord Syndromes and Their Management. Proceedings of the Congress of Neurological Surgeons, Clinical Neurosurgery Williams and Wilkins Co. p $424-487$.

SCHNEIDER RC, KAHN EA (Oct) 1956 Chronic neurological sequelae of acute trauma to the spine and spinal cord, fournal of Bond and foint Surgery 38A:985.

SCHNEIDER RC, THOMPSON JM, BEBIN J 1958 The syndrome of acute central cervical spinal cord injury, fournal of Neurology Neurosurgery Psychiatry 21:216.

STOOKEY B (Aug) 1928 Compression of spinal cord due to ventral extradural cervical chondromas, diagnosis and surgical treatment, Archives of Neurology and Psychiatry 20:275. 